\title{
ADAPTATION TO FLOODING EVENTS THROUGH VULNERABILITY MAPPING IN HISTORIC URBAN AREAS
}

\author{
Alessandra Gandini ${ }^{1}$, Iñaki Prieto ${ }^{1}$, Leire Garmendia ${ }^{2}$, José-Tomás San-José ${ }^{3}$, Aitziber Egusquiza ${ }^{1}$ \\ ${ }^{1}$ Sustainable Construction Division, Tecnalia Research \& Innovation, Spain - (Alessandra.gandini, inaki.prieto, \\ aitziber.egusquiza)@tecnalia.com \\ ${ }^{2}$ Department of Mechanical Engineering. University of the Basque Country UPV/EHU, Spain - leire.garmendia@ehu.eus \\ ${ }^{3}$ Department of Metallurgical Engineering and Materials Science. University of the Basque Country UPV/EHU - \\ josetomas.sanjose@ehu.es
}

Commission VI, WG VI/4

KEY WORDS: Cultural heritage, flooding, climate change, urban data model, vulnerability assessment

\begin{abstract}
:
Historic urban areas are complex and inter-reliant systems, vulnerable to natural hazards. Over the recent years, the increase frequency in extreme precipitation events and sea-level rise, have impacted on a large number of historic areas, growing concern over disaster mitigation related to climate change.

Most of the changes in the climatological indicators may have adverse impacts on historic areas, leading to physical, social and cultural consequences and should be included in urban planning practice. The importance of addressing cultural heritage in disaster risk has also been included in The Sendai Framework, considering the dimensions of vulnerability, adaptive capacity and exposure through systematic evaluation.

Urban planning decisions involve an understanding of complex interactions between different aspects of the city, in its constructive, social, economic, environmental and cultural system. The analysis of these interactions requires a systemic approach as the components operate on different spatial and temporal scales and generate a large amount of data. This information can be used to determine the vulnerability of historic areas by assessing it at the building level, through the creation of typologies representing the building stock, often characterized by similarities and common constructive elements.

The comprehension of the information can be supported and homogenized by a multi-scale urban model, to facilitate the understanding of interactions and the link among the different disciplines involved. This paper describes the methodology proposed for vulnerability mapping in historic urban areas, by using a categorization method supported by an information strategy and a multiscale urban model.
\end{abstract}

\section{INTRODUCTION}

During the last decades, cultural heritage has been threatened by diverse conditions such as demographic change, mass tourism and climate change, which are posing new challenges to conservation practice. Many restorative or conservative approaches of historic areas are still linked to single monuments or group of buildings, leaving aside the overall urban setting, the socio-economic conditions and the public spaces which are part of a more complex, living and dynamic ecosystem. Cultural heritage areas are seen as belonging to the past and disconnected from the present and from each other (Moylan et al. 2009).

Historic areas and the heritage that shape them, form interdependent systems within nowadays cities. Conservation strategies and policies should therefore consider the changing environment as an added element of planning and find a balance between urban growth and quality of life in a sustainable way. Physical forms, spatial organization, natural features and social, cultural and economic values should be therefore interrelated. This is only feasible through a holistic vision and the integration of specific oriented policies, such as disaster risk management and cultural heritage conservation, within wider goals of overall sustainable development (Kelman et al. 2015).

The effective management of historic areas, especially in disaster prone areas, should be based on a new generation of information and adapted strategies, involving local communities and predictive or possible future scenarios. The development of new and integrated urban governance dynamics calls for a complex, multidisciplinary and interdisciplinary approach involving a cross-section of different stakeholders and decision makers.

As climate change and its related negative impacts have become more widely accepted, its scope has broadened, shifting from the management of the hazard direct physical manifestation to disaster risk management approaches, considering the variables of exposure, vulnerability and hazard (IPCC 2014). The uncertainty of climate change and its possible impacts calls for iterative risk management approaches, involving different profiles and levels of stakeholders in all the phases of the decision-making scenario: prevention, preparedness, response and recovery.

As part of the prevention phase, possible impacts on cultural heritage and its vulnerability should be addressed as a first step towards the increase of resilience of historic areas. Climate change impacts, with the support of appropriate data and information, have been assessed by a wide range of methods and tools, as they can vary widely, depending on the subject, time frame, geographic coverage and purpose of the assessment (UNFCCC 2011). 
Vulnerability assessment is needed to respond to the new challenges of climate change and the increasing number of disasters cities are currently or will in the next future have to face. Furthermore, a deep analysis of the vulnerabilities helps to improve current management strategies for preparedness, emergency as well as recovery phases. However, it should be noted, that vulnerability in general might be interpreted in several ways depending on the focus of the assessment (ENSURE 2013).

From one hand, urban planning involves the understanding of complex interactions among different domains, such as the constructive, social, economic, environmental and cultural system, which are characterized by a large amount of information. From the other hand, climate change and related disaster events are driving reassessment of the ways urban settlements are conceived and prepare to respond to new impacts in a more sustainable way. Addressing climate change and cities entails the analysis of both the changing climate and city system, which leads to several scientific challenges (Masson et al. 2014). In order to organize and structure all the information able to guide the understanding of these interrelations and interactions, urban modelling is one of the available tools that can be used to support evidence-based decision-making.

The work described in this paper describes the methodology proposed for vulnerability mapping in historic urban areas, by using a categorization method supported by an information strategy and a multi-scale urban model.

The rest of this paper is structured as follows: Section 2 describes the followed methodological approach; Section 3 presents the vulnerability in the case of San Sebastian; and, finally, the conclusions and future work section closes the paper.

\section{METHODOLOGICAL APPROACH}

\subsection{Building stock categorization method}

Vulnerability to climate change and related hazards with a sufficient level of confidence, is often available on a macroscale, while cultural heritage vulnerability is assessed on a micro-scale, using a one-by-one methodology, implying time and resource consuming field surveys. Local governments are not usually keen to assume such compromise, especially if the area threatened is wide. There is therefore need to find a balance between the two scales, considering both the regional or local territory as well as the single building vulnerabilities. This compromise can be found by modelling the building stock through a statistical distribution of its main characteristics.

Research related to disaster risk has been traditionally oriented to the hazard itself rather that the relatively more recent field of vulnerability. The primary causes of risk, hazard severity, vulnerability of the constructive elements of the city and recovery capabilities are not often clarified and specified. There is a lack of standardized, accessible and reliable data sources and protocols for urban models responding to climate change and the sustainability agenda, as this field of research is still largely fragmented (OECD 2011).

Information on the characteristics and vulnerability of buildings and infrastructure is essential to enable a quantification of the exposure. But the collection of this information should be done by the use of resource efficiency methodologies, enabling at the same time a sufficiently realistic and accurate result.

Building stock can be described in terms of sample buildings, meaning that detailed data of representative buildings is used as input information to the model. The methodology is able to capture a relevant variety of buildings within the stock which can be used to identify areas of highest vulnerability.

The building stock is usually heterogenous, so it is necessary to dive it into categories which share common parameters and similarities, usually defined as the categorization process. The selection of parameters to build categories represents one of the main sensitive steps. Representativeness, number of categories created and relevance of the information considered are the main characteristics to be considered. The categorization process is not unique and depends on the historic area considered, as well as on data availability. If all parameters are considered the result will be a huge number of categories. It is therefore necessary to select a proper threshold that will divide the parameter into diverse ranges, but it is also necessary to discard the less representative groups. For each category a reference building can be defined by means of a suitable procedure (Ballarini et al. 2014). When a large building stock is examined by means of a statistical approach, only the detailed characteristics/properties of a sample building are considered. The characteristics of sample buildings are then extrapolated to the whole building stock. Again, the process for selecting the proper sample building for each category should follow some requirements, which depend on data availability, the representativeness of the building itself of the category and the historic area characteristics(Prieto et al. 2017).

\subsection{Integrated Value Model for Sustainable Assessment}

The transition of historic cities towards a more sustainable and integrated planning, including adaptive measures against climate change impacts and disasters, requires for a comprehensive participation of stakeholders and profiles, with different backgrounds and interests in several cross-thematic sectors. In order to implement successful actions, decision should be taken considering the understanding of the needs of each actor and address the salient issue of each one (Khare et al. 2011), based on a win-win strategy.

In order to facilitate the decision-making process, several multicriteria approaches have been developed and applied (Zavadskas et al. 2014). Among these models, the Integrated Value Model for Sustainable Assessment (MIVES), developed by the Polytechnic University of Catalonia (UPC), Tecnalia and the University of the Basque Country (UPV/EHU), has demonstrated its applicability in diverse complex scenarios related to sustainability (Pardo-Bosch \& Aguado 2015; Piñero et al. 2017). The model combines two different concepts: MultiCriteria Decision-making Theory and Value Engineering (SanJosé Lombera \& Garrucho Aprea 2010).

In the MIVES methodology, the whole model is established prior to the generation of alternatives, thus defining all aspects which are relevant for the decision itself. The phases of the decision process are the followings:

1. Problem definition and decision to be taken: defines who makes the decision, fixes the limits of the system and establishes the boundary conditions 
2. Decision support tree definition: establishes all the issues to be considered in an organized way, in the form of a requirements tree (hierarchy)

3. Setting the value functions: generates mathematical functions that allow the transformation of quantitative and qualitative aspects into a set of variables with the same unit, between 0 and 1

4. Weight assignment: assigns the relative importance of one aspect compared to others

5. Alternatives evaluation: obtains the value index for each of the proposed alternatives

The application of MIVES in vulnerability assessment is used to give homogeneity to the different types of parameters considered and collected through the sample buildings method. As the values considered are measured in different units, the methodology transforms them in the same dimensionless unit, taking into account the relative importance of the aspects under considerations. Environmental, social, economic and technical indicators are therefore considered under the same and unique vulnerability index.

\subsection{Multiscale urban data models}

Over the recent years, due to their information and storage capabilities, 3D digital georeferenced urban models have gained importance. The 3D visualization makes the semantic information of urban models more accessible and natural, facilitating the spatial analysis and the collaboration among the diverse stakeholders' profiles involved in the management, conservation, use and planning of historic urban areas.

The main drawback and limitation of existing representation of urban 3D models such as Google Earth, Bing 3D or CityEngine is the lack of semantic information. A pure geometric 3D city model can be only used for visualization purposes. A semantic 3D city model contains urban knowledge and semantic information, having attributes of different city elements and relations between them. CityGML is the most widely used standard for the representation of $3 \mathrm{D}$ city models. This OGC standard allows to combine geometric and semantic information, supports multiple levels of detail (Egusquiza et al. 2014) and makes it possible to combine data at different scales (Catita et al. 2014), from the territory to the buildings (Biljecki et al. 2015; Kolbe et al. 2013).

The goal is to link thematic information and characteristics regarding buildings and urban environments with geometric information in a single integrated data model. The standard CityGML has been identified as the data model that allows 3D geo-referenced and semantic information associated with geometry to be stored in a single data model (Gröger et al. 2012). Moreover, the interoperability of the standard with Geographic Information Systems (GIS) and Building Information Models (BIM), supposes a link with data models more focused in the building or territorial scales extending the multi-scale capabilities of the model.

CityGML allows coherent modeling between geometry and semantics. The standard includes some semantic properties for the objects defined in CityGML, however the data included in the CityGML core are generally not sufficient to cover the requirements of the users or the applications to be developed based on that urban model (Tegtmeier et al. 2014). For this purpose, CityGML defines the Application Domain Extension (ADE) concept. Several ADEs have been defined for different domains and purposes by different research groups (Aydar et al. 2016; Coccolo et al. 2016), but none are integrated within a workflow of the generation and maintenance of $3 \mathrm{D}$ city models.

The interoperability is one of the key advantages of an information model based on a standard such as CityGML, since it facilitates the connection with other data models and other analysis, management and decision-making tools and enables the generation of a service ecosystem to make urban planning and management easier, through the creation of new cloudbased applications (Chen 2011). Within this ecosystem, services for efficient management of energy resources, for the administration and optimization of urban mobility, for tourist, cultural and service information, for e-government and participation can be designed (Gröger \& Plümer 2012).

The need to consider climate change and disaster scenarios as part of the city planning, will contribute to the generation of further critical information, which should be considered as part of the sustainable development. If the correct balance between data acquisition and accuracy of results is achieved, the inclusion of all this information in a unique data model can provide a solution for the decision-making process.

\section{VULNERABILITY ASSESSMENT}

\subsection{Creation of the data model}

The CityGML data model has been completed for the case study of San Sebastian, Spain. The area selected for the implementation of the vulnerability assessment methodology is located next to the boundaries of the Urumea river and is formed of 6 districts, comprising 2,262 lots. The data model was completed with semantic information available from public data sources. Most of the parameters at the building level have been collected from the Spanish cadastre and have been processed to automatically be included in the data model. Most of the parameters at district level are obtained from the climate database of the Spanish meteorological agency and are manually introduced into the data model. As a result, all lots of the case study are represented in LoD2 by independent facades and the roof. The building height has been obtained from LiDAR data.

The basic semantic data included in the model are the following:

1. Reference number of the lot

2. Year of construction

3. Use

4. Existence of a basement

5. Cultural value

6. Number of dwellings

7. Socio-economic status

\subsection{Building stock categorization}

In order to generate the categories of the building stock and, according to the statistical overview of the area, the use, level of protection, existence of a basement and status were considered as primary parameters, with a threshold of minimum representation established in a $2 \%$. Furthermore, 1950 was considered as the date on which to divide categories, as it is relevant for the division between historic and new buildings as well as for similarities in constructive materials. As a result of the analysis, 15 categories were established. Figure 1 shows the 
geographical distribution of the typologies within a 3D visualization in the building stock categorization tool.

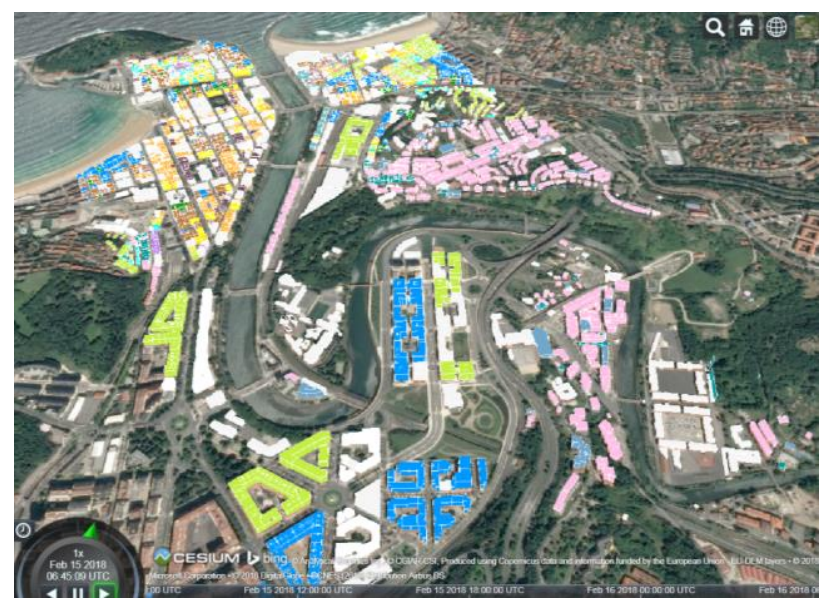

Figure 1 Building stock categorization result visualization

Once obtained the relevant categories, sample buildings were selected according to the representativeness of the parameters compared to the whole category and the availability of relevant information. These are real buildings that are representative enough of a group of elements with the same characteristics. For the vulnerability calculation, semantic information on the sample buildings was completed and extrapolated to the category, according to the following data:

1. State of conservation

2. Existence of water damage

3. Ground floor typology

4. Openings on ground floor

5. Roof type

6. Façade material

7. Structural material

8. Existence of adaptive systems

9. Drainage system conditions

10. Previous interventions

The additional semantic information of the sample buildings was collected through fieldwork.

\subsection{Vulnerability calculation}

Vulnerability index has been calculated by the use of the MIVES methodology, by creating a requirement tree based on the concept that is traditionally used in climate change adaptation with the purpose of integrating different disciplines. The main requirements that have been used to assess the vulnerability are sensitiveness and adaptive capacity.

The hierarchical structure of the requirements tree defines three levels: requirements, criteria, and indicators. In the first levels, namely the requirements and criteria, general and qualitative aspects are defined, while in the last level, the indicators, concrete and measurable aspects are considered. Requirements, criteria and indicators have the objective of representing what we want to evaluate, avoiding the repetition of certain aspects or avoiding the use aspects which are out of scope. Indicators selected should therefore be representative, differentiating, complementary, relative, quantifiable and traceable (Josa 2012).
The sensitiveness requirement has the objective of assessing the degree to which a building is affected by an event. Depending on the conditions, typology and characteristics of the structure that is considered, its response to climate impacts varies. Criteria related to this requirement are therefore associated to the current state of the building, constructive critical elements, envelope characteristics, main use, and structural material.

The requirement of adaptive capacity refers to the ability of a system to assume the potential effects of an event, overcoming its consequences. In this case, criteria refer to interventions, socio-economic conditions and the cultural value of the buildings.

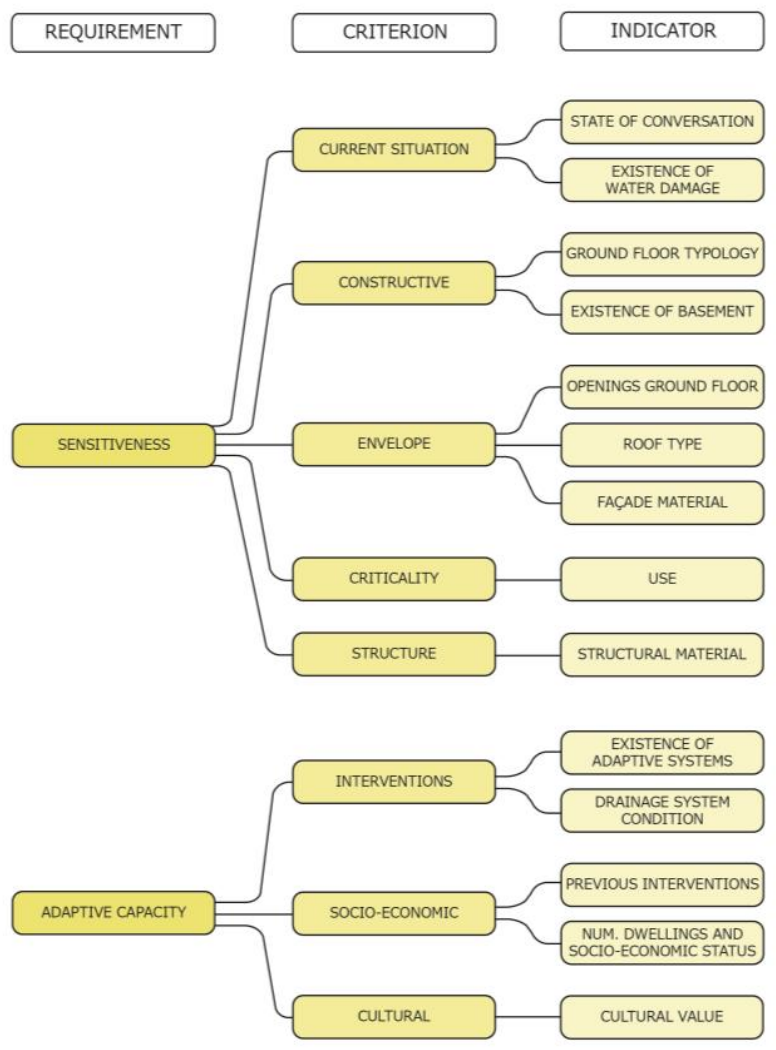

Figure 2 Requirements tree for vulnerability assessment

Once the requirements tree have been defined in all its level, Analytic Hierarchy Process (AHP) (Saaty 1980) was used for the weights assignment, by establishing the relative importance of each branch of the requirements tree. Weights have been assigned by member of an expert panel, starting from the calculation of the $\gamma$ weights of the indicators, followed by the $\beta$ weights of the criteria, and lastly by the $\alpha$ weights of the requirements. Weight assignment is performed by comparing elements at the same level and in the same branch of the requirements tree. Thus, the indicator weights are calculated according to other indicators belonging to the same criterion. In the same manner, a criterion weight is calculated by other criteria belonging to the same requirement.

By including the sample buildings semantic information in the data model, the tool allows to obtain a unique vulnerability index, which is calculated according to the weighting process. Once the vulnerability for each representative building has been 
established, it is possible to extrapolate the result for the entire study area, giving the same value to all the buildings belonging to the same category, as can be seen in Figure 3.

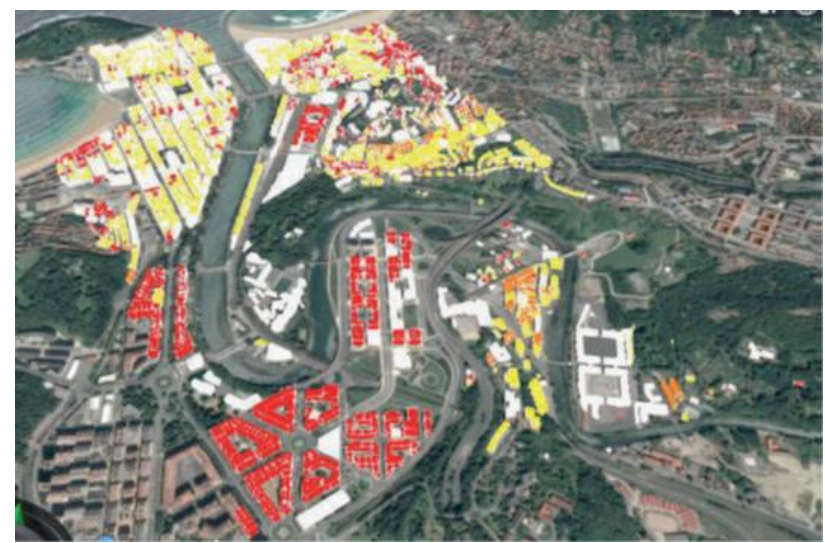

Figure 3 Building vulnerability index visualization

As additional functionality, the tool allows also the visualization of different flood maps using WMS services, as can be seen in Figure 4.

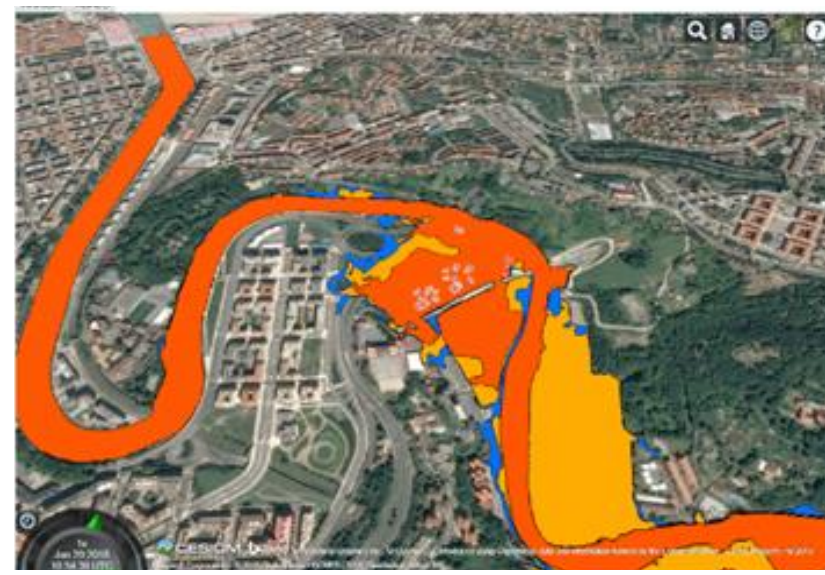

Figure 4 Flood maps visualization

\section{CONCLUSIONS AND FUTURE WORK}

The main objective of the work presented in this article is the implementation of a methodological approach that facilitate decision-making in the adaptation to flooding events in historic areas, using a multiscale urban data model. The vulnerability is calculated first, identifying the sample building of the case study by mean of building stock categorization method; second, using MIVES methodology to calculate the vulnerability maps.

The development of 3D city models based on the OGC CityGML standard allows city and building levels to be integrated within a single model that includes both semantic and geometric information. Such a model can be used to support multiple applications that different agents, such as urban planners, managers and citizens may employ.

The buildings stock categorization is based on a modelling strategy based on sample buildings. The described method for building stock categorization proposes a reduced an easily acquired set of parameters (year of construction, use, existence of basement, cultural value and socio-economic status) that gives optimal balance between the number of typologies and the represented percentage of the building stock.

The vulnerability index has been calculated by structuring the information in hierarchical levels and by comparing indicators of different nature through the use of value functions. MIVES has been used to help the decision-making process based on multicriteria analysis by using the multi-stakeholders' perspective, enabling an integrated analysis of aspects considered. The result is a final and unique vulnerability index which yields a ranking vulnerability of sample buildings.

The validation of the sample building modelling strategy and MIVES methodology in the case study of San Sebastian was carried through a survey campaign in 100 buildings, which were inspected, in order to check the accuracy of results obtained. The comparison between the categorization method and the use of real data resulted in a margin of error of $9 \%$.

The work presented in this paper is mainly focused in assessing building vulnerability according the structure and architectural characteristics of the building itself. Other kinds of analysis, such as economic loss, impacts on natural landscapes, and social studies can complement the vulnerability assessment.

The results presented in this paper open several possibilities for future work. First of all, the model can be extended for its use in the implementation phase, by including scenario simulations of possible adaptive measures. Furthermore, the inclusion of real tome data coming from different sources such as sensors or satellite images, can further expand the use of the model in the response and recovery phases.

\section{ACKNOWLEDGEMENTS}

Authors would like to acknowledge the funding provided by the Basque Government through the ADVICE project and the research group IT781-13 at the UPV/EHU.

\section{REFERENCES}

Aydar, S.A. et al., 2016. Establishing a national 3D geo-data model for building data compliant to citygml: Case Of Turkey. In International Archives of the Photogrammetry, Remote Sensing and Spatial Information Sciences - ISPRS Archives. pp. 79-86.

Ballarini, I., Corgnati, S.P. \& Corrado, V., 2014. Use of reference buildings to assess the energy saving potentials of the residential building stock: The experience of TABULA project. Energy Policy, 68, pp.273-284.

Biljecki, F. et al., 2015. Applications of 3D City Models: State of the Art Review. ISPRS International Journal of GeoInformation, 4(4), pp.2842-2889.

Catita, C. et al., 2014. Extending solar potential analysis in buildings to vertical facades. Computers and Geosciences, 66 , pp.1-12.

Chen, R., 2011. The development of 3D city model and its applications in urban planning. 2011 19th International Conference on Geoinformatics, pp.1-5.

Coccolo, S. et al., 2016. Integration of outdoor human comfort in a building energy simulation database using CityGML 
Energy Ade. In Expanding Boundaries-Systems Thinking in the Built Environment-Proceedings of the Sustainable Built Environment (SBE) Regional Conference Zurich 2016.

Egusquiza, A., Prieto, I. \& Romero, A., 2014. Multiscale information management for sustainable districts rehabilitation : EFFESUS and FASUDIR projects. In eWork and eBusiness in Architecture, Engineering and Construction ECPPM 2014. pp. 303-308.

ENSURE, C., 2013. Final Report - ENSURE (Enhancing resilience of communities and territories facing natural and natech hazards).

Gröger, G. et al., 2012. OGC City Geography Markup Language (CityGML) En-coding Standard. Ogc, pp.1 - 344.

Gröger, G. \& Plümer, L., 2012. CityGML - Interoperable semantic 3D city models. ISPRS Journal of Photogrammetry and Remote Sensing, 71, pp.12-33.

IPCC, 2014. Summary for policymakers. In M. D. M. Field, C.B., V.R. Barros, D.J. Dokken, K.J. Mach, S. M. T.E. Bilir, M. Chatterjee, K.L. Ebi, Y.O. Estrada, R.C. Genova, B. Girma, E.S. Kissel, A.N. Levy, \& and L. L. W. P.R. Mastrandrea, eds. Climate Change 2014: Impacts, Adaptation, and Vulnerability. Part A: Global and Sectoral Aspects. Contribution of Working Group II to the Fifth Assessment Report of the Intergovernmental Panel on Climate Change. Cambridge University Press, pp. 1-32.

Josa, A., 2012. Introducción a MIVES y el análisis multicriterio.

Kelman, I., Gaillard, J.C. \& Mercer, J., 2015. Climate change's role in disaster risk reduction's future: Beyond vulnerability and resilience. International Journal of Disaster Risk Science, 6(1), pp.21-27.

Khare, A., Beckman, T. \& Crouse, N., 2011. Cities addressing climate change: Introducing a tripartite model for sustainable partnership. Sustainable Cities and Society, 1(4), pp.227-235.

Kolbe, T.H., Nagel, C. \& Herreruela, J., 2013. 3D City Database for CityGML, Berlin.

Masson, V. et al., 2014. Adapting cities to climate change: A systemic modelling approach. Urban Climate, 10(P2), pp.407429.

Moylan, E., Brown, S. \& Kelly, C., 2009. Toward a Cultural Landscape Atlas: Representing all the Landscape as Cultural. International Journal of Heritage Studies, 15(5), pp.447-466.

OECD, 2011. Effective Modelling of Urban Systems to Address the Challenges of Climate Change and Sustainability Organisati.

Pardo-Bosch, F. \& Aguado, A., 2015. Investment priorities for the management of hydraulic structures. Structure and Infrastructure Engineering, 11(10), pp.1338-1351.

Piñero, I. et al., 2017. Multi-criteria decision making for grading the rehabilitation of heritage sites. Application in the historic center of La Habana. Journal of Cultural Heritage, 26, pp.144-152.
Prieto, I., Izkara, J.L. \& Egusquiza, A., 2017. Building stock categorization for energy retrofitting of historic districts based on a 3D city model. DYNA INGENIERIA E INDUSTRIA, In press.

Saaty, T.L., 1980. The Analytic Hierarchy Process. Education, pp.1-11.

San-José Lombera, J.T. \& Garrucho Aprea, I., 2010. A system approach to the environmental analysis of industrial buildings. Building and Environment, 45(3), pp.673-683.

Tegtmeier, W. et al., 2014. 3D-GEM: Geo-technical extension towards an integrated 3D information model for infrastructural development. Computers and Geosciences, 64, pp.126-135.

UNFCCC, 2011. Assessing climate change impacts and vulnerability, making informed adaptation decisions United nations Framework convention on climate Change, ed.,

Zavadskas, E.K. et al., 2014. Multi-criteria analysis of Projects' performance in construction. Archives of Civil and Mechanical Engineering, 14(1), pp.114-121. 